\title{
Immigrant Political Representation and Local Ethnic Concentration: Evidence from a Swedish Refugee Placement Program
}

\author{
Karl-Oskar Lindgren $^{1 \star}$ (D), Michael D. Nicholson ${ }^{2}$ and Sven Oskarsson ${ }^{1}$ \\ ${ }^{1}$ Department of Government, Uppsala University, Uppsala, Uppland, Sweden and ${ }^{2}$ Center of Migration Studies, New York, \\ USA \\ ${ }^{\star}$ Corresponding author. Email: karl-oskar.lindgren@statsvet.uu.se
}

(Received 13 June 2019; revised 15 October 2020; accepted 30 November 2020; first published online 24 February 2021)

\begin{abstract}
This study leverages population registry data from Sweden to examine whether immigrants who live in areas with a high concentration of ethnic minorities are more or less likely to be nominated for political office. It exploits a refugee placement program in place in Sweden during the late 1980s and early 1990s that restricted refugees' opportunities to freely choose their place of residence. The article presents evidence that immigrants who live in areas with a high ethnic density are less likely to be nominated for political office. The findings have important implications for local integration policies as well as refugee placement policies, as many countries consider local context when resettling refugees.
\end{abstract}

Keywords: ethnic concentration; political candidacy; under-representation

In recent years, the question of how the residential segregation of immigrants and ethnic minorities affects their social inclusion has received increased attention in both academic and policy circles. Including immigrants in politics is frequently regarded as essential to the legitimacy of liberal democracies (Mansbridge 1999). The fact that immigrants are less likely than natives to vote in elections in many countries (for example, de Rooij 2012; Wass et al. 2015), and are less well represented in important political bodies (for example, Bloemraad 2013; Dancygier et al. 2015), thus constitutes an important societal challenge. It is therefore important to explore whether residential segregation hinders or fosters immigrants' political integration.

Despite the importance of this issue, few studies have investigated the link between ethnic concentration and political integration. Prior research has almost exclusively focused on immigrant voter turnout, and the findings differ between studies. Research situated in the United States has tended to find a negative relationship between ethnic concentration and turnout (Cho 1999; Cho, Gimpel and Dyck 2006), whereas studies from Europe have found a positive relationship (Bhatti and Hansen 2016; Fieldhouse and Cutts 2008a; Fieldhouse and Cutts 2008b).

A methodological difficulty plaguing research on this issue, however, is that the results may be affected by immigrants self-sorting into different types of neighborhoods. Those who choose to settle in areas with a high concentration of ethnic minorities, for example, may have unobserved traits and characteristics that make them more or less likely to engage with politics. This selfsorting can make it difficult to identify the effect of ethnic concentration on immigrants' political integration. If the nature of this self-sorting differs between ethnic groups, countries and contexts, this difference could potentially help explain the conflicting results found in previous studies. 
Another limitation of existing research is the rather narrow focus on voter turnout. Turnout is no doubt very important, but there are other equally vital aspects of incorporating immigrants into the political system. In particular, the under-representation of immigrants in democratically elected bodies is often discussed as an indication of their insufficient political integration into their new host countries (Bloemraad 2013).

This article addresses both of these limitations using high-quality data from Swedish registers to study the relationship between ethnic concentration and immigrants' local political representation. We investigate whether immigrants who settle in areas with a high proportion of co-ethnics are more or less likely to be nominated to local political office. To mitigate the problem of self-sorting into different types of neighborhoods, we leverage data from a comprehensive placement policy that was in place in Sweden between 1985 and 1994, which severely restricted refugees' ability to choose where they initially settled when they arrived in Sweden.

Following the early work of Edin, Fredriksson and Åslund (2003), who used the placement policy to study labor market outcomes, we argue that the policy's implementation generated exogenous variation in immigrants' residential contexts that can be used to credibly identify the effect of ethnic concentration on immigrants' local political representation. That is, the fact that refugees did not get to choose their own initial location substantively reduces the risk that the empirical results are driven by the type of sorting bias discussed above.

The current study thus contributes to previous research in two key respects. First, and perhaps most importantly, we broaden the focus beyond voter turnout and study how ethnic concentration affects the likelihood of becoming a political representative. To the best of our knowledge, ours is the first quantitative study to explicitly examine this relationship. Secondly, compared to previous research on voter turnout, our study benefits from having access to a stronger identification strategy, which allows us to rely on less stringent modelling assumptions when estimating the effect of interest. ${ }^{1}$

We find evidence that immigrants are substantially less likely to be nominated for political office as the share of co-ethnics in the municipality in which they settled increases - suggesting that high levels of ethnic residential concentration may contribute to immigrants' underrepresentation in local political bodies.

These results are important, since understanding the sources of immigrants' political underrepresentation is vital to strengthening representative democracy. Given that many countries consider the local context when resettling refugees and asylum seekers, understanding the long-term impact of local ethnic concentration on immigrants' subsequent political integration is of particular policy importance. In this regard, our findings lend some credibility to the view that dispersal policies that discourage ethnic concentration can encourage immigrants' long-term political representation. Moreover, since political participation constitutes an important aspect of immigrant integration, these results could also be taken to indicate that immigrant dispersion can help ease integration more generally.

\section{Ethnic Concentration and Immigrant Political Representation}

In party-based systems, the political representation of immigrants is the result of both supply- and demand-side factors (Norris and Lovenduski 1995). That is, two conditions must be met for immigrants to appear on party lists. First, enough immigrants must choose to engage in politics and be ready to stand as candidates if asked to do so (the supply-side condition). Secondly, party selectors and gatekeepers must be willing to recruit and nominate candidates with an immigrant background (the demand-side condition). When theorizing on the relationship between ethnic residential

\footnotetext{
${ }^{1}$ A companion research note by Andersson et al. (2021), which uses a similar empirical design as the current study to examine the relationship between ethnic concentration and voter turnout, constitutes a partial exception in this regard. Andersson et al. (2021) find that immigrant turnout is unrelated to the overall degree of ethnic concentration, but that living with many politically active co-ethnics may facilitate voting.
} 
concentration and immigrant representation, we therefore ought to consider the potential effects of ethnic concentration on both the supply and demand of immigrant candidates.

There is no consensus in the literature on whether ethnic residential concentration facilitates or hinders immigrant political integration. For instance, it has been suggested that immigrants who live in areas with a high concentration of ethnic minorities, and who therefore interact disproportionally with individuals of their own ethnic origin (Vervoort 2012), are less likely to participate in politics because they have relatively limited access to information about host-country politics, and tend to focus their attention on the politics of their country of origin rather than the host country (Cho, Gimpel and Dyck 2006; Piore 1979). Moreover, it has been argued that ethnic concentration may impede immigrants' opportunities to learn the host-country language and enter the regular labor market (cf. Bolt, Özuekren and Philips 2010), two factors that are known to be associated with immigrants' political involvement (Cho 1999). Individual-level factors such as these are most directly linked to the supply of immigrant candidates, although they can also indirectly affect the demand for such candidates.

However, less frequent interactions with natives can also have a more direct effect on representation through the demand side. For instance, some studies have suggested that access to recruitment networks 'explains a substantial part of structurally related differences in political participation' between immigrants and natives (Strömblad and Myrberg 2013, 1050). Therefore, it can be hypothesized that immigrants living in less ethnically concentrated areas stand a greater chance of being recruited into politics, since their personal networks are more likely to contain (native) political insiders.

Other scholars, however, claim that ethnic residential concentration may instead spur political participation. For instance, ethnic communities can be an important resource to help immigrants navigate a new political context: they can help increase the flow of information within immigrant groups, ultimately facilitating their mobilization (Fieldhouse and Cutts 2008a; Laurence and Heath 2008; Lipset et al. 1954; Maxwell 2013). Ethnic concentration may also encourage participation by fostering group consciousness (Bilodeau 2009); when the local proportion of immigrants from a group increases, more immigrants engage in politics as they come to perceive that engagement benefits them and their group (Leighley 2001). To the extent that ethnic concentration fosters rather than hinders immigrant economic integration, as some scholars have argued (Edin, Fredriksson and Åslund 2003; Wilson and Portes 1980), this could also increase their political integration (Verba and Nie 1972). Finally, still others argue that increased ethnic concentration may primarily affect immigrant representation by increasing the demand for immigrant candidates, particularly when earning immigrants' support could tip the scales in competitive elections (Ciornei 2014; Dancygier 2017; Maxwell 2012).

To summarize, existing theoretical arguments about the impact of ethnic concentration on immigrant political representation point in different directions. Whereas some scholars believe ethnic concentration reduces the supply of (and demand for) immigrant political candidates, others argue the opposite. Ultimately, it is an empirical question whether ethnic concentration hinders or facilitates immigrant political representation. However, as mentioned in the introduction, few studies have been conducted on the topic. The present study therefore aims to shed additional light on the effect of ethnic concentration on immigrant political representation by leveraging a Swedish refugee placement program, which we describe in more detail in the next section. This research design allows us to identify the overall (net) effect of ethnic concentration on immigrant representation. However, it is less able to distinguish the individual contributions of the various supply and demand factors discussed in this section.

\section{Immigration to Sweden and the Refugee Placement Policy}

Sweden's history of migration resembles the experiences of other European countries. In the 1950s and 1960s, the inflow of immigrants to Sweden was made up largely of labor migrants. 
These came primarily from Finland, but migrants from Central and Southern Europe and Turkey were recruited to the manufacturing sector as well (Lundh and Ohlsson 1999; Nilsson 2004).

In the aftermath of the oil crisis and increasing unemployment in the early 1970s, the demand for foreign labor dwindled. The share of labor migrants has since decreased, and refugees and family reunification migrants have dominated immigrant inflows. This pattern accelerated in the late 1980s and early 1990s following a massive increase in immigration (Dancygier et al. 2015). About one-fifth of Sweden's current population was born abroad.

Another feature shared by most Western countries is the concentration of immigrants in certain regions and neighborhoods (Åslund et al. 2011). In Sweden, large cities such as Stockholm, Gothenburg and Malmö host around half of the country's foreign-born population but only around a third of the total population. Within these regions, immigrants are over-represented in particular areas, especially suburbs.

In response to mounting complaints from the cities with the largest increases in immigration, the policy framework regulating the reception of refugee immigrants underwent a drastic reform in $1985 .^{2}$ The Swedish Immigration Board was given the responsibility of assigning all newly arrived asylum seekers to an initial municipality of residence.

The main goal of this reform was to speed up asylum seekers' integration process by distributing them across a larger group of municipalities with above-average educational, labor market and housing opportunities. At the start of the reform, the board signed contracts with around sixty receiving municipalities. However, due to the large increase in the number of asylum seekers in the late 1980s, the Immigration Board decided that all Swedish municipalities should receive asylum seekers. By 1989, the system included 277 of the country's 284 municipalities. The goal was to place at least 2.9 refugees per thousand inhabitants in each municipality. The original educational and labor market opportunities criteria were abandoned. Available public housing instead became the main governing principle. According to Anders Wenström, the head of the Swedish Ministry of Employment's integration division during the placement reform, refugees were often placed in newly built subdivisions and apartment complexes, where the 'chance of finding other immigrants or refugees in there before them was quite substantial', although the degree of ethnic concentration varied across municipalities (Wenström 2013).

The placement policy was formally in effect between 1985 and 1994, but the implementation was strictest between 1987 and 1991. Therefore, our analysis focuses on refugees arriving during the 1987-1991 period. A number of previous works have used the placement reform to study the effects of ethnic concentration on immigrant economic success (Edin, Fredriksson and Åslund 2003), peer effects on immigrant student achievement and welfare dependence (Åslund and Fredriksson 2009; Åslund et al. 2011), and the relationship between income inequality and health (Grönqvist, Johansson and Niknami 2012).

Our identification strategy rests on the assumption that the settlement policy provides an exogenous source of variation in contextual characteristics. More concretely, an individual's residence in an area with high co-ethnic density must not be linked to unobserved factors that might influence his or her propensity to be nominated to local political office.

The studies mentioned above substantiate these claims. The essence of the argument rests on three facts. First, the policy was comprehensive: between 1987 and 1991, the Immigration Board assigned a large majority - around 90 per cent - of the refugees to different municipalities.

Secondly, immigrants' preferences did not play a decisive role in the assignment process. Although refugees could apply for residence in their preferred city or area, local Immigration Board officers decided on the placement of individual refugees. The explicit goal of the placement policy was to reduce the time between receiving a residence permit and placement in a

\footnotetext{
${ }^{2}$ This section is mainly based on Edin et al. (2003), Åslund and Fredriksson (2009), Borevi and Myrberg (2010), Åslund et al. (2011) and Grönqvist et al. (2012).
} 
municipality; the main obstacle in this process was a lack of housing. The housing market was very tight in the late 1980s, especially in the larger cities. Thus housing vacancies would have had to have coincided with immigrants' receipt of residence permits for their residential preferences to be honored. The very low probability of these two events happening concurrently ensured that little, if any, weight was given to immigrant preferences in the assignment process. Ultimately, the 'availability of housing was the prime governing factor' determining immigrants' placement (Wenström 2013).

Thirdly, there was no interaction between local Immigration Board officers and individual refugees in the placement process. Any selection by local officers was driven solely by observable characteristics, particularly immigrants' language, formal education and family size. We thus argue that immigrants' municipal assignment was exogenous with respect to unobserved individual factors, conditional on these observed characteristics.

\section{Data and Methods}

We obtained all data used in the empirical analysis from various administrative registers held by Statistics Sweden (see the Appendix for a more detailed description of the data and variables). As mentioned above, we focus on refugees who immigrated between 1987 and 1991 . Unfortunately, refugees cannot be identified directly from the data. Instead, we follow the approach of Åslund and Fredriksson (2009), who include immigrants from countries outside of Western Europe that were not members of the OECD as of 1985. Their only exception to this rule is that they include Turkey, an important source of asylum seekers during the period of interest. Given that the placement policy did not apply to family migrants, we exclude all immigrants with a sibling or adult household member who immigrated to Sweden in an earlier year. Like Åslund and Fredriksson (2009), we also restrict the analysis to individuals aged 18-55 at the time of immigration. Imposing these restrictions yields a sample of 62,230 immigrants that we follow in the seven general elections held in 1991, 1994, 1998, 2002, 2006, 2010 and 2014.

We use political nomination for the municipal council as our dependent variable. During the study period, the number of municipalities increased from 284 to 290 . Swedish municipalities are responsible for a wide range of important public goods and services, including childcare, primary and secondary schooling, and care for the elderly. Municipalities also have independent income taxation rights and employ large shares of the labor force.

Each municipality is governed by a municipality council elected every fourth year (every third year before 1994) in elections held on the same day as national and regional elections. All individuals over the age of 18 who have lived in Sweden for at least three years are eligible to vote and stand as a candidate for the municipal council. ${ }^{3}$ Municipal elections in Sweden operate according to a party-list system. Thus candidates can only be elected to the municipal council via parties. Members and subgroups in all parties can nominate their favorite candidates. Local nomination committees then rank the nominated candidates who agreed to run based on popularity and representativity in terms of gender, age, ethnic background, experience and political standpoints. Party gatekeepers are thus highly influential in deciding who is on the list and in what position. Though voters may, since 1998, cast preference votes for specific candidates, the list position still nearly exclusively determines winning (see Dancygier et al. 2015 for a more detailed description).

Previous research has shown that immigrant groups are still severely politically underrepresented in Sweden. Studying the probability of being nominated and elected to municipality councils, Dancygier et al. found that in 2010, natives were twice as likely as immigrants to be elected and 1.7 times as likely to be nominated to political office (2015, Tables 2 and A5).

\footnotetext{
${ }^{3}$ Since 1998, citizens from other Nordic or EU countries have been eligible to vote and stand as a candidate in local elections as long as they have moved to Sweden at least 30 days before the election.
} 
We focus on immigrants' probability of nomination rather than election for methodological reasons. Although we have access to data for the entire population, our sample only includes 192 individuals who were elected to political office at least once during the study period, which severely decreases the statistical power. The number of nominated individuals is 1,009 , which gives us somewhat better precision in the estimates. Our choice of dependent variable can also be defended on theoretical grounds. First, the fact that more than 99 per cent of all eligible individuals do not appear on a party list during a given election reflects the vital role of candidate selection. Put simply, the real hurdle in Swedish politics is not getting elected, but getting one's name on the party list in the first place. Secondly, a failure to get elected does not necessarily preclude individuals at the lower end of the party lists from reaching different political positions, as non-elected candidates are commonly used to populate the many municipality boards and committees.

Turning to the key independent variable, we rely on the logarithm of ethnic density to measure ethnic concentration for the bulk of the analysis. Ethnic density is simply the percent of the municipality's total population that any given ethnic group comprises. ${ }^{4}$ To calculate our ethnic density measures, we use immigrants' country of birth. For reasons of confidentiality, the country of birth variable has been grouped into twenty-seven distinct groups. For immigrants from significant sending countries (such as Iran, Iraq and Turkey) the region code is that of the country, but for those from other countries the code also includes neighboring countries (the Appendix provides the full classification together with a frequency table of the relative size of the different groups). Although we would have preferred to have access to country of birth information for all immigrants, our robustness checks suggest that the aggregation does not unduly affect our main findings.

As can be seen from the descriptive statistics presented in the first column of Table 1, only a small share of the individuals in our sample ended up as nominees in the 1991 to 2014 elections. On average, the probability of being nominated to municipal council in this group was 0.6 per cent, whereas the probability of election was as low as 0.1 per cent. These figures highlight the fact that large data sets are needed to analyze these questions.

From the descriptive statistics, we can also see that the individuals in our sample immigrated at the age of 30 on average, had around 11 years of schooling, and were somewhat more likely to be male than female. Taking the average across all years, municipalities and country groups, ethnic density in our sample is about 0.5 per cent.

As expected, the share of immigrants who are still living in the municipality in which they were initially placed decreases over time. At the time of the 1991 election, about 62 per cent of the immigrants in our sample remained in their assigned municipality, compared to 38 per cent in 2014 (see Appendix Figure A1). However, the individuals who decided to stay in their assigned municipality and those who chose to move appear to be very similar in most important respects (see Appendix Table A3).

\section{Statistical Estimation}

In this study, we use the Swedish placement program discussed above to help mitigate the potential bias due to immigrants self-sorting into areas with high co-ethnic densities. We follow the approach employed by Edin, Fredriksson and Åslund (2003) and use the ethnic composition of the initial (assigned) municipality to instrument for ethnic concentration in later years. ${ }^{5}$ Through instrumentation, we attempt to identify the effect of ethnic concentration on candidacy

\footnotetext{
${ }^{4}$ In the Appendix we discuss the theoretical and methodological advantages of using the log of ethnic density instead of the raw shares.

${ }^{5}$ For similar approaches to estimating the effects of ethnic enclaves on labor market outcomes in Denmark and Switzerland, see Piil Damm (2009) and Martén, Hainmueller and Hangartner (2019).
} 
Table 1. Descriptive statistics

\begin{tabular}{|c|c|c|c|}
\hline \multirow[b]{2}{*}{ Variables } & \multirow[b]{2}{*}{ Full sample } & \multicolumn{2}{|c|}{ Initial placement } \\
\hline & & Low density & High density \\
\hline Age & $\begin{array}{c}44.79 \\
(10.78)\end{array}$ & $\begin{array}{c}44.29 \\
(10.48)\end{array}$ & $\begin{array}{c}45.30 \\
(11.05)\end{array}$ \\
\hline Female & $\begin{array}{c}0.42 \\
(0.49)\end{array}$ & $\begin{array}{c}0.40 \\
(0.49)\end{array}$ & $\begin{array}{c}0.44 \\
(0.50)\end{array}$ \\
\hline Married & $\begin{array}{c}0.59 \\
(0.49)\end{array}$ & $\begin{array}{c}0.57 \\
(0.49)\end{array}$ & $\begin{array}{c}0.60 \\
(0.49)\end{array}$ \\
\hline Nr. of children under 16 & $\begin{array}{c}1.03 \\
(1.32)\end{array}$ & $\begin{array}{c}1.06 \\
(1.36)\end{array}$ & $\begin{array}{c}1.01 \\
(1.28)\end{array}$ \\
\hline Years of education & $\begin{array}{l}10.80 \\
(2.73)\end{array}$ & $\begin{array}{l}10.82 \\
(2.75)\end{array}$ & $\begin{array}{c}10.79 \\
(2.71)\end{array}$ \\
\hline Ethnic density (log) & $\begin{array}{c}-4.63 \\
(0.90)\end{array}$ & $\begin{array}{c}-4.87 \\
(0.94)\end{array}$ & $\begin{array}{c}-4.38 \\
(0.78)\end{array}$ \\
\hline Nominated (\%) & $\begin{array}{c}0.58 \\
(7.51)\end{array}$ & $\begin{array}{c}0.74 \\
(8.54)\end{array}$ & $\begin{array}{c}0.43 \\
(6.55)\end{array}$ \\
\hline Elected (\%) & $\begin{array}{c}0.10 \\
(3.16)\end{array}$ & $\begin{array}{c}0.12 \\
(3.48)\end{array}$ & $\begin{array}{c}0.08 \\
(2.80)\end{array}$ \\
\hline Age at immigration & $\begin{array}{c}30.44 \\
(8.11)\end{array}$ & $\begin{array}{l}29.94 \\
(7.68)\end{array}$ & $\begin{array}{c}30.94 \\
(8.50)\end{array}$ \\
\hline Immigration year & $\begin{array}{r}1988.96 \\
(1.36)\end{array}$ & $\begin{array}{r}1988.92 \\
(1.38)\end{array}$ & $\begin{array}{r}1988.99 \\
(1.33)\end{array}$ \\
\hline Observations & 349,383 & 174,671 & 174,712 \\
\hline
\end{tabular}

Note: the table reports means and standard deviations (in parentheses) for three different samples. Low (high) density refers to individuals for whom ethnic density in the assigned municipality is below (above) the median value.

by isolating the portion of contemporaneous ethnic concentration that was driven uniquely by concentration at the time of initial settlement. This method identifies the effect of ethnic concentration on immigrants who remained in their initial municipality of assignment in the year of each respective election. The first and second stages of the two-stage least-squares (2SLS) model are specified as follows:

$$
\begin{aligned}
& E_{i g m t}=\alpha E_{g m t_{0}}+\boldsymbol{\Gamma} \boldsymbol{X}_{i t}+\delta_{g}+\delta_{t_{0}}+\delta_{m_{0}}+\eta_{i g m t} \\
& Y_{\text {igmt }}=\beta \hat{E}_{i g m t}+\boldsymbol{\Theta}^{\prime} \boldsymbol{X}_{i t}+\delta_{g}+\delta_{t_{0}}+\delta_{m_{0}}+\boldsymbol{\epsilon}_{\text {igmt }}
\end{aligned}
$$

where $i$ indexes individuals, $m$ municipalities, $g$ ethnic groups and $t$ time. In the first stage, we regress ethnic concentration in each election year $\left(E_{\text {igmt }}\right)$ on ethnic concentration in the assigned municipality, measured at the time of placement $\left(E_{g m t_{0}}\right)$. In the second stage, $Y_{\text {igmt }}$, which is a binary indicator for being nominated for political office $(1=$ nominated, $0=$ not nominated $)$, is regressed on the predicted scores from the first stage. Ethnic concentration constitutes the (logged) number of individual i's co-ethnics relative to the total number of individuals in municipality $m$.

As discussed above, there are some indications in previous research that Immigration Board officers might have taken easily observed individual characteristics into account when deciding where to place new immigrants. We therefore control for a number of individual-level characteristics in our model $\left(\boldsymbol{X}_{i t}\right)$, such as gender, formal education at the time of placement, family size at the time of placement and year of birth. More importantly, to further reduce the risk of omitted variable bias, the regressions also include a full set of country-of-origin fixed effects $\left(\delta_{g}\right)$, immigration year fixed effects $\left(\delta_{t 0}\right)$ and fixed effects for assigned municipality $\left(\delta_{m 0}\right)$. Notice here that the effect of ethnic concentration is identified even if we include fixed effects for assigned 
municipality, since there is variation in group size both across and within ethnicities in a municipality. That is, the effect of ethnic concentration on candidacy will be identified by comparing individuals from different countries (groups) that arrived in Sweden in the same year and were placed in the same municipality. Likewise, we can also identify the effect by comparing individuals from the same country (group) who were placed in the same municipality but arrived in adjacent years. Moreover, the fixed effects for arrival municipality will pick up the impact of all municipality characteristics that are constant for all immigrants assigned to a particular municipality, such as its population size.

The identifying assumption underlying our empirical analysis is thus that the immigrants' initial placement, during the period when the placement policy was in place, can be considered exogenous conditional upon the covariates included in the model. The argument is thus not that refugee placement was completely random during the period of interest. For instance, Columns 2 and 3 of Table 1 illustrate that the immigrants placed in municipalities with low ethnic concentration were not equal to those placed in municipalities with high ethnic density in all relevant respects. The assumption is instead that the Immigrant Board officers had to assign refugees to municipalities on the basis of the observed individual characteristics included as controls in our model, such as age, gender, education and family situation. Unfortunately, it is very difficult to test the tenability of the conditional exogeneity assumption directly, since it would require access to variables that are related to the outcome of interest (for example, innate ability) and that were not available to (or considered by) the Immigrant Board officer deciding on the placement. ${ }^{6}$

However, as discussed above, previous research on the topic has gathered a substantial amount of circumstantial evidence in support of the view that the placement policy considerably reduces, if perhaps not totally eliminates, the self-sorting problems that typically plague studies of ethnic concentration (Åslund and Fredriksson 2009; Edin, Fredriksson and Åslund 2003; Grönqvist, Johansson and Niknami 2012). We believe the most convincing piece of evidence is the major change in settlement patterns induced by the reform, which is illustrated in Figure 1.

The graph shows the share of newly arrived refugee (solid line) and non-refugee (dashed line) immigrants that settled in the ten municipalities with the highest proportion of inhabitants from refugee-sending countries in 1984 (the year before the settlement program was introduced). Before the introduction of the placement policy this share was above 50 per cent in both groups, but it decreased substantially for the refugee immigrants - the ones affected by the policy - after the policy was put in place. After the policy was abolished in 1994, the settlement patterns of the two groups once again converged. This indicates that the policy had a substantial impact on the residential location of refugee immigrants.

Consequently, there is clear evidence that the placement policy considerably reduced refugees' ability to settle in the municipality of their choice. Given that the case officers deciding on their placement did not get to meet with newly arrived refugees, it also appears very unlikely that placements should correlate with any important unobserved individual characteristics. We therefore find the conditional exogeneity assumption plausible.

Whereas this assumption is sufficient to obtain a causal estimate of the effect of initial ethnic concentration on political activity, the 2SLS procedure discussed above requires us to make an additional assumption. That is, we need to assume that the effect of initial ethnic density on candidacy is fully transmitted through current ethnic density (the so-called exclusion restriction). Although we cannot completely rule out the possibility that initial ethnic density could have a direct and long-lasting effect on political engagement, we believe it is reasonable to assume that current ethnic density mediates most of the effect.

\footnotetext{
${ }^{6}$ See Nekby and Pettersson-Lidbom (2017) and Dahlberg, Edmark and Berg (2017) for two different views on the severity of this problem.
} 


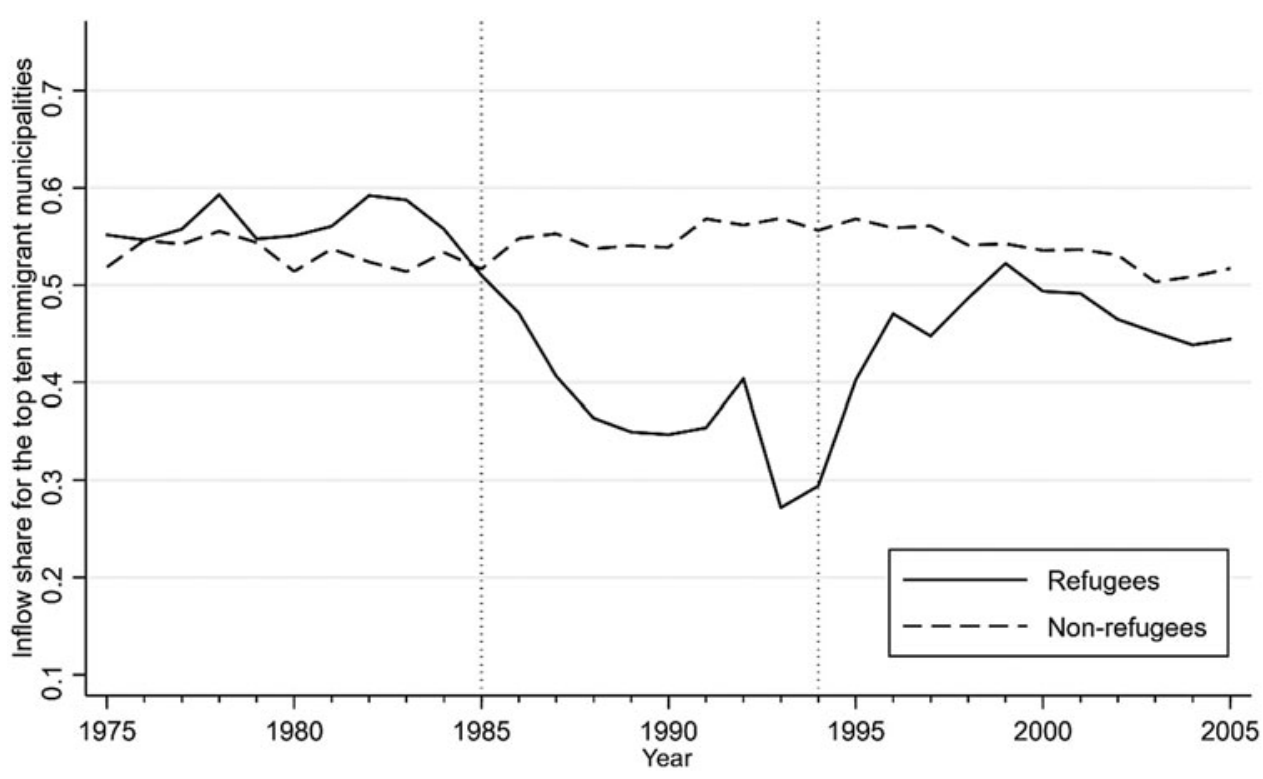

Figure 1. The effect of the placement policy on immigrant settlement

Note: the top ten immigrant municipalities are the ten municipalities that had the largest share of inhabitants from refugee-sending countries in 1984.

\section{Empirical Results}

Table 2 displays the results of the basic specification in which the outcome of interest is whether an individual was nominated for a seat on the municipal council in any of the seven elections held between 1991 and 2014. For most of this analysis we use a linear probability model because the instrumental variables approach becomes much more involved when applied to non-linear models such as logit or probit. However, we also examine the results from an instrumental variables probit model as a robustness check.

Columns 1 and 4 of Table 2 report standard ordinary least squares (OLS) estimates with election year municipality fixed effects. That is, we compare immigrants living in the same municipality at the time of the election. This is the same type of specification used by Bhatti and Hansen (2016) to study the relationship between ethnic concentration and voter turnout. In Columns 2 and 5, we make additional use of the placement program by replacing the election year municipality fixed effects with immigration year municipality fixed effects to compare the outcomes of individuals who were initially assigned to the same municipality. Finally, in Columns 3 and 6 we keep the assigned municipality effects, but also use ethnic density for each immigrant's initial placement as an instrument for ethnic density in election years.

The first set of estimates presented in Columns 1 and 4 illustrates that an increase in ethnic concentration of one log unit is associated with a $0.1-0.15$ percentage point decrease in the probability of nomination for political office in a given election. Comparing the results across both columns shows that controlling for a more extended set of individual demographic characteristics only marginally affects the results. This is also the empirical specification that comes closest to that used in previous research on the topic (Bhatti and Hansen 2016; Fieldhouse and Cutts 2008b).

However, if we replace the election year municipality fixed effects with assigned municipality fixed effects, as we do in Models 2 and 5, the negative effect of ethnic density on candidacy becomes considerably more marked. Increasing (log) ethnic concentration by one unit is now estimated to decrease the likelihood of political nomination by about 0.4 percentage points. 
Table 2. Relationship between political candidacy and ethnic density

\begin{tabular}{|c|c|c|c|c|c|c|}
\hline & 1 & 2 & 3 & 4 & 5 & 6 \\
\hline Ethnic density & $\begin{array}{c}-0.143^{\star \star \star} \\
(0.043)\end{array}$ & $\begin{array}{c}-0.410^{\star \star \star} \\
(0.045)\end{array}$ & $\begin{array}{c}-0.437^{\star \star} \\
(0.162)\end{array}$ & $\begin{array}{c}-0.115^{\star \star \star} \\
(0.044)\end{array}$ & $\begin{array}{c}-0.396^{\star \star \star} \\
(0.045)\end{array}$ & $\begin{array}{c}-0.368^{\star \star} \\
(0.162)\end{array}$ \\
\hline Female & & & & $\begin{array}{c}-0.185^{\star \star \star} \\
(0.051)\end{array}$ & $\begin{array}{c}-0.173^{\star \star *} \\
(0.040)\end{array}$ & $\begin{array}{c}-0.172^{\star \star \star} \\
(0.040)\end{array}$ \\
\hline Married & & & & $\begin{array}{l}0.173^{\star *} \\
(0.074)\end{array}$ & $\begin{array}{l}0.171^{\star \star \star} \\
(0.056)\end{array}$ & $\begin{array}{l}0.170^{\star \star \star} \\
(0.056)\end{array}$ \\
\hline Education & & & & $\begin{array}{l}0.099^{\star \star \star *} \\
(0.016)\end{array}$ & $\begin{array}{l}0.094^{\star \star \star} \\
(0.012)\end{array}$ & $\begin{array}{l}0.095^{\star \star \star} \\
(0.012)\end{array}$ \\
\hline Children & & & & $\begin{array}{c}-0.016 \\
(0.022)\end{array}$ & $\begin{array}{c}-0.008 \\
(0.020)\end{array}$ & $\begin{array}{c}-0.008 \\
(0.020)\end{array}$ \\
\hline First stage & & & $\begin{array}{l}0.274^{\star \star \star} \\
(0.022)\end{array}$ & & & $\begin{array}{l}0.271^{\star \star \star} \\
(0.022)\end{array}$ \\
\hline Reduced form & & & $\begin{array}{l}-0.120^{\star \star \star} \\
(0.043)\end{array}$ & & & $\begin{array}{c}-0.100^{\star \star} \\
(0.043)\end{array}$ \\
\hline Mun. FE & Elec. Year & Imm. Year & Imm. Year & Elec. Year & Imm. Year & Imm. Year \\
\hline Method & OLS & OLS & $2 S L S$ & OLS & OLS & $2 S L S$ \\
\hline Observations & 349,383 & 349,383 & 349,383 & 349,383 & 349,383 & 349,383 \\
\hline
\end{tabular}

Note: all models include fixed effects for election year, year of birth, country of origin and year of immigration. In addition, the OLS models include municipality fixed effects and instrumental variables models fixed effects for assigned municipality. Standard errors are shown in parentheses and allow for clustering within election year (Models 1 and 4 ) or assigned municipalities (Models $2,3,5,6) .^{* \star *} /{ }^{* \star} /{ }^{*}$ indicate significance at the $1 / 5 / 10$ per cent level.

A problem with both previous specifications is that although initial placement was arguably random under the placement program, it may not be random which immigrants decide to move where in later years. The previous results could therefore be affected by immigrants systematically self-sorting into particular types of neighborhoods, even though they did not get to choose their original residency.

To check whether this is the case, we can use the instrumental variable approach discussed above and instrument ethnic density at the time of the election with ethnic density at the time of arrival. Models 3 and 6 present the results from this exercise. Comparing these results to those of the models that include the extended set of individual controls reveals that the magnitude of the ethnic density coefficient decreases by about 15 per cent when adjusting for self-sorting in later years. However, the point estimate is still statistically significant and more than three times as large as that obtained in the first specification, which compared individuals living in the same municipality at the time of the election rather than immigrants originally placed in the same municipality. The results presented in Column 6 show that a one-unit increase in (log) ethnic concentration decreases the likelihood of nomination by an estimated 0.37 percentage points. Alternatively, increasing ethnic density from the twenty-fifth to the seventy-fifth percentile reduces the probability of nomination by 0.44 percentage points. Given that the baseline probability of nomination in this group is as low as 0.6 per cent, this is a substantively important effect.

To get an even better sense of the magnitude of this effect, Figure 2 illustrates the relationship between the predicted probability of nomination and the actual, rather than the logarithmic, ethnic share (this graph is based on the results in Column 6 of Table 2). The figure shows that the probability of nomination decreases substantially as ethnic density increases. According to these results, an immigrant living in a municipality where ethnic concentration corresponds to the fifth percentile ( 0.14 per cent) is more than six times as likely to be nominated for office than a similar individual living in a municipality where ethnic density is at the ninety-fifth percentile (2.8 per cent).

Another important issue concerns the strength of the instrument used in the analysis. The first-stage coefficients reported at the bottom of Table 2 demonstrate the instrument's strong predictive power. A one-unit increase in (log) ethnic density in the assigned municipality increases (log) ethnic density in later years by 0.27 units, and the effect is highly statistically significant (the 


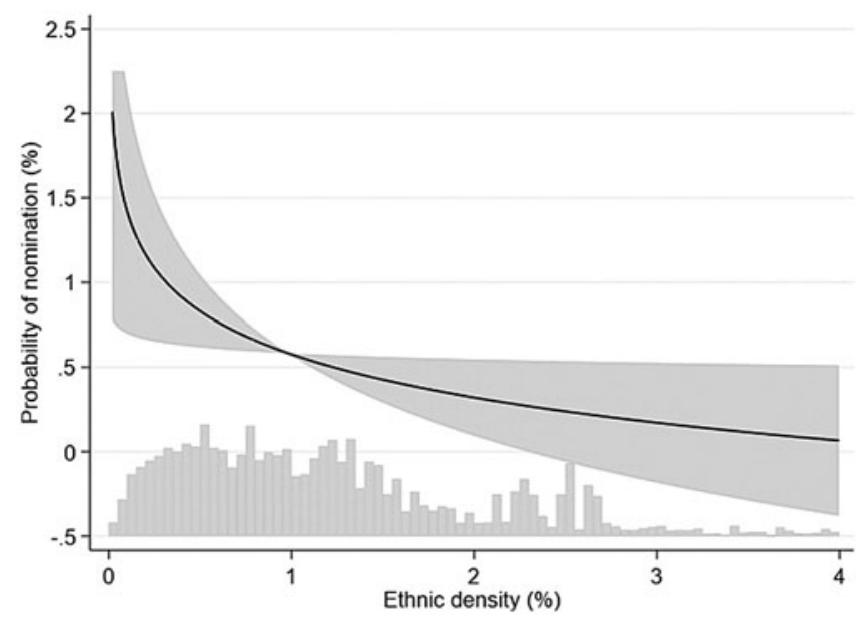

Figure 2. Predicted probability of nomination by ethnic density

F-statistic of the first stage is 152). Concretely, this means that enough immigrants remained in place over time for the level of ethnic concentration at assignment to affect ethnic concentration at later points in time. ${ }^{7}$ Moreover, additional analyses indicate that the first-stage and reducedform relationships appear to be approximately linear (see Appendix Figures A2-A7), which further corroborates the validity of our instrumental variable approach.

As noted above, the standard approach in previous studies has been to examine the importance of ethnic concentration by comparing the political activity of individuals from different ethnic groups who live in the same political unit at a specific point in time, as we do in Columns 1 and 4 of Table 2. However, if we compare these results with those obtained when we restrict the comparison to individuals who were initially placed in the same municipality, the negative effect of ethnic concentration on political nomination is considerably stronger in the latter case. Since the placement program reduced immigrants' ability to self-sort into particular neighborhoods, the difference in results across the two specifications could indicate that the standard approach underestimates the negative effect of ethnic concentration on candidacy due to self-sorting.

The results presented above suggest that ethnic residential segregation has a negative effect on immigrants' likelihood of being nominated for political office. The Appendix reports the results of numerous sensitivity analyses conducted to check the robustness of these findings. These analyses show that our findings are not unduly driven by immigration to large urban areas or the lumping together of immigrants from small source countries (Table A4). We obtain very similar results (see Table A6) if we control for the type of political opportunity structure variables examined by Dancygier et al. (2015). Moreover, we find that the results look very similar when using probit regression (Table A4), when controlling for covariates in a more flexible manner (Table A5), and if we dichotomize both the treatment variable and the instrument (Table A5). Although the negative effect of ethnic density weakens somewhat when not log transforming the ethnic density variable (Table A4), as we discuss in the Appendix, there are both theoretical and methodological reasons to conduct the log transformation in this case. Finally, we used the approach suggested by Marbach and Hangartner (2019) to examine the group of so-called compliers in order to assess the generalizability of our instrumental variable results. The outcome of this latter exercise is not clear-cut. We find that the group of compliers deviates slightly from the

\footnotetext{
${ }^{7}$ If we multiply the first-stage coefficient by the ethnic density coefficient, we obtain an estimate of the so-called reducedform effect. The reduced-form coefficient together with its standard error is reported at the bottom of Table 2.
} 
main sample in some regards, although we do not believe these deviations are large enough to affect the generalizability of our findings (Figure A8).

Finally, to shed further light on the implications of our results, we also conducted some tentative analyses on how ethnic concentration affects the qualifications and performance of immigrant candidates. We find that immigrant candidates from municipalities with a high ethnic concentration are, on average, somewhat more educated, more likely to be elected, are placed further up on the party lists, and receive slightly more preference votes than those from municipalities with a low ethnic density (see Appendix Table A9). This could indicate that although ethnic concentration negatively affects the number of immigrant candidates, those who do appear on the party lists in contexts of high ethnic concentration are somewhat more successful. However, none of these differences reaches conventional levels of statistical significance, so more research is needed before we can draw any firm conclusions about the impact of ethnic concentration on candidate qualifications/performance.

\section{Mechanisms}

What mechanisms are driving the observed negative relationship between residential segregation and political representation? While a more in-depth analysis of the causal mechanisms at work is unfortunately beyond the scope of this study due to data constraints, we use the available register data to try to shed at least some light on this important issue.

In the theory section, we highlighted two possible mediators of the relationship between ethnic concentration and immigrants' political representation - socio-economic status and factors related to assimilation. To examine these assertions, we perform a simple mediation analysis. We first consider the possibility that the effect of residential segregation on candidacy is channeled through socio-economic status (Verba and Nie 1972) by adding controls for earnings, current education and employment to our preferred specification.

The results are presented below in Table 3. The first column of the table reproduces the estimate from our preferred specification to ease comparison. As expected, the results after adding socio-economic controls suggest that earnings, education and employment are strongly and positively related to candidacy status. Moreover, the coefficient of the ethnic density variable decreases slightly (by about 9 per cent) when controlling for socio-economic status, but given the size of the standard errors of the various coefficients, this reduction should not be overinterpreted. This finding suggests that, even if ethnic concentration influences immigrants' socio-economic status, such changes in status do not seem to mediate the relationship between residence in enclaves and political nomination to any large extent.

We next test the classical assimilation hypothesis, which holds that residence in ethnic 'enclaves' limits immigrants' contact with natives, potentially limiting their political socialization and exposure to information about host-country politics. In Column 3, we add a dummy variable indicating whether an individual has a Swedish-born partner. The variable takes a value of 1 for those with a Swedish-born partner and 0 for those who are single or have a foreign-born partner. It proxies for immigrants' ties to individuals born in Sweden. Although we find that having a Swedish-born partner is a strong predictor of candidacy, the coefficient of the ethnic density variable decreases only marginally when adding this control to the model. Column 4 also adds the share of Swedish-born colleagues to the model: this variable records the share of Swedish-born individuals employed at the same workplace as the immigrant (coded 0 for individuals without employment). Once again, the estimated effect of ethnic concentration hardly changes at all as a result. We thus find little direct evidence to support the assimilation mechanism. Yet our operationalization of interactions with natives is admittedly rather narrow and indirect; it is possible that we would obtain different results if we had access to a more direct measure of cross-group interactions.

Admittedly, our operationalization of potential mechanisms is limited, and the mediation analysis of the type performed here rests on strong modeling assumptions (Imai et al. 2011). 
Table 3. Mediation analysis

\begin{tabular}{lcccc}
\hline & 1 & 2 & 3 & 4 \\
\hline Ethnic density & $-0.368^{\star \star}$ & $-0.340^{\star \star}$ & $-0.322^{\star}$ & $-0.321^{\star}$ \\
& $(0.163)$ & $(0.162)$ & $(0.164)$ & $(0.165)$ \\
Earnings & & $0.009^{\star \star \star}$ & $0.009^{\star \star}$ & $\left(0.008^{\star \star}\right.$ \\
& & $(0.003)$ & $(0.003)$ & $(0.003)$ \\
Education & & $0.128^{\star \star}$ & $0.126^{\star \star}$ & $\left(0.125^{\star \star \star}\right.$ \\
Employed & $(0.021)$ & $0.021)$ & $(0.021)$ \\
Native partner & $0.228^{\star \star \star}$ & $(0.046)$ & $0.167^{\star \star}$ \\
Share native colleagues & $(0.046)$ & $0.364^{\star \star}$ & $(0.054)$ \\
& & & $(0.142)$ & $0.358^{\star \star}$ \\
& & & & $(0.141)$ \\
\end{tabular}

Observations

339,845

339,845

339,845

339,845

Note: all models include fixed effects for election year, year of birth, country of origin, year of immigration and assigned municipality, as well as controls for gender, marital status, number of children and education at the time of immigration. Clustered standard errors in parentheses. ${ }^{* \star \star} /{ }^{* \star} /{ }^{*}$ indicate significance at the $1 / 5 / 10 \%$ level.

Nevertheless, we consider our simple mediation analyses to be a valuable first step towards understanding why residential segregation affects immigrants' likelihood of being nominated for political office. Above all, the results are valuable in helping to rule out potential mechanisms. To judge from these results, the observed effect is not, to any large extent, channeled through either socio-economic status or exposure to natives at home or in the workplace.

An alternative means of identifying the mechanisms underlying a causal relationship is to examine the extent to which the effect of interest is driven by particular sub-groups in the data. One might ask, for example, the extent to which the effect of ethnic concentration varies with municipalities' political characteristics, especially the relative strength of right- and left-wing parties. For instance, if the negative effect of ethnic concentration is more marked in municipalities where the demand for immigrant candidates can be expected to be higher, this could indicate that ethnic concentration affects immigrant representation mainly by reducing the supply of immigrant candidates.

To check whether this is the case, we conducted a number of heterogeneity analyses. In Figure 3, we show how the effect of ethnic concentration varies with left party support, strength of the populist right, and the disproportionality of the electoral system. ${ }^{8}$ Whereas the effect of concentration appears to be about the same whether parties to the left or right dominate the municipality, there are some (although fairly weak) indications that the negative effect of ethnic concentration is more marked where right populist parties are weak and the disproportionality of the electoral system is low. Given that previous research suggests that immigrant political representation is negatively affected by both the strength of right populist parties and a high disproportionality of the electoral system (for example, Dancygier et al. 2015), these results are consistent with the view that ethnic concentration affects immigrant representation by decreasing the supply of immigrant candidates. However, the poor precision of these estimates precludes any firm conclusions in this regard.

We also performed a number of additional heterogeneity analyses to examine whether the effect of ethnic concentration varies with individual characteristics such as sex, education and citizenship status. Although we find some differences in the point estimates with respect to

\footnotetext{
${ }^{8}$ To measure right populist support in a municipality, we use the vote shared received by the New Democrats (Ny demokrati) in the 1991 parliament election. The New Democrats was a populist and anti-immigration party that was represented in the Swedish parliament between 1991-1994. To measure disproportionality, we use the Gallagher index, i.e., $G=\sqrt{0.5\left(\sum\left(v_{i}-s_{i}\right)^{2}\right)}$, where $v$ and $s$ indicate the vote and seat shares of party $i$, respectively.
} 


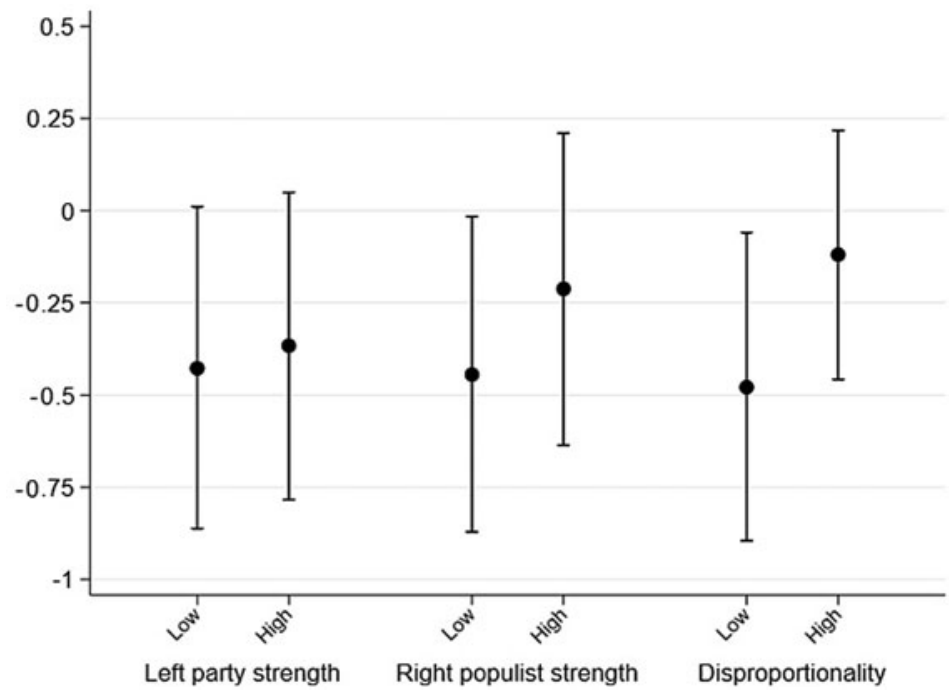

Figure 3. Effect of ethnic concentration by political context

Note: the dots represent point estimates and the error bars 95 per cent confidence intervals. Left party strength is based on the total vote share of the three left parties: the Social Democrats, the Left Party and the Green Party. If these three parties received less (more) than 50 per cent of the votes in a particular municipality this measure is set to low (high). Low (high) right populist strength indicates that the vote support for the New Democrats in 1991 was below (above) the median in a municipality, and low (high) disproportionality indicates that the Gallagher index of disproportionality was below (above) the median in a municipality. See Appendix Table A7 for the complete results.

education and citizenship status, none of the differences reaches conventional levels of statistical significance (see Appendix Table A8).

\section{Conclusion}

In this study, we present evidence that immigrants residing in areas with a high ethnic concentration are less likely to be nominated to local political office. This finding has important implications for local immigrant integration efforts as well as refugee placement policies. Specifically, our results suggest that dispersal policies might support the political representation of immigrants over time.

Our findings make three valuable contributions to the existing literature. First, to our knowledge, this is the first quantitative article relating local ethnic density to immigrants' political representation. Secondly, Sweden's unique individual registry data on candidacy, encompassing both winning and losing candidates, enables us to analyze the determinants of immigrant political engagement in an unprecedented manner. Thirdly, most studies to date have examined data on minority population 'stock' without accounting for self-sorting into ethnic neighborhoods (Borjas 1995; Cutler, Glaeser and Vigdor 2008). By leveraging the exogeneity of Sweden's historical refugee placement program, our findings limit biases that sorting might otherwise engender.

Our analysis also provides some tentative insights into possible mechanisms linking residence in areas with a high ethnic density to decreased participation. Somewhat surprisingly, we find little evidence that ethnic concentration decreases participation by limiting immigrants' contact with native Swedes, although our operationalization of native contacts is fairly narrow and indirect. Further, this relationship does not appear to be mediated by immigrants' socio-economic status. Data constraints do not allow us to gauge whether immigrants' residence in such areas alters their participation by changing their attitudes towards host-country politics. However, our findings highlight the need for further research in this vein - particularly gauging whether residence in areas with a high ethnic density depresses immigrants' sense of political efficacy. 
Ultimately, this article represents only an early step towards a better understanding of the effect of local context on minorities' political representation. For instance, the settlement program studied here was limited to refugees. It is plausible that our results may thus not generalize to economic migrants or family reunification migrants with differing experiences of political socialization in their homelands and upon arrival in Sweden. In particular, some refugees may be less familiar with democratic politics than non-refugee immigrants (Portes and Mozo 1985). Future work might therefore examine the relationship between residence in areas with a high ethnic concentration and political candidacy among economic and family reunification migrants.

Future studies should also explore the mechanisms through which neighborhood context may influence minorities' likelihood of becoming a political representative. In a context of rising nationalism and burgeoning anti-immigrant sentiment across developed democracies, research in this vein may support efforts to improve minority representation and, ultimately, safeguard minorities' rights.

Acknowledgements. We are grateful for the detailed and helpful comments provided by three anonymous reviewers and the editor René Lindstädt. We also thank the participants at the 2017 IMISCOE (International Migration, Integration and Social Cohesion in Europe) conference in Rotterdam.

Data availability statement. The data used in this article is restricted access and maintained by Statistics Sweden. A detailed description of how to get access to these data, together with the computer code to replicate all our analyses, are available at https://doi.org/10.7910/DVN/DDVYJI.

Supplementary material. Online appendices are available at https://doi.org/10.1017/S0007123420000824.

Financial support. This work was supported by the European Research Council (grant number 683214), and the Swedish Research Council (grant number 2017-00764).

Conflicts of interest. None.

Ethical standards. This research was conducted in Sweden and was approved by the Regional Ethical Review Board in Uppsala (approval number 2016/164).

\section{References}

Andersson $\mathrm{H}$ et al. (2021) Effects of settlement into ethnic enclaves on immigrant voter turnout, forthcoming. Journal of Politics.

Åslund $\mathbf{O}$ et al. (2011) Peers, neighborhoods, and immigrant student achievement. American Economic Journal: Applied Economics 3, 67-95.

Åslund O and Fredriksson P (2009) Peer effects in welfare dependence. Journal of Human Resources 44(3), 799-825.

Bhatti $\mathbf{Y}$ and Hansen KM (2016) The effect of residential concentration on turnout among ethnic minorities. International Migration Review 50(4), 977-1004.

Bilodeau A (2009) Residential segregation and the electoral participation of immigrants in Australia. International Migration Review 43(1), 134-159.

Bloemraad I (2013) Accessing the corridors of power. West European Politics 36(3), 652-670.

Bolt G, Özuekren AS and Philips D (2010) Linking integration and residential segregation. Journal of Ethnic and Migration Studies 36, 169-186.

Borevi K and Myrberg G (2010) Välfärdsstaten och de nyanlända [The welfare state and the newly arrived]. MIM Working Papers Series No. 10:3.

Borjas G (1995) The economic benefits from immigration. The Journal of Economic Perspectives 9(2), 3-22.

Cho W (1999) Naturalization, socialization, participation. Journal of Politics 61(4), 1140-1155.

Cho W, Gimpel J and Dyck J (2006) Residential concentration, political socialization, and voter turnout. Journal of Politics 68(1), 156-167.

Ciornei I (2014) The political candidacy of EU migrants in their countries of residence. The case of British and Romanians standing in Spanish local elections. Journal of Ethnic and Migration Studies 40(9), 1375-1393.

Cutler D, Glaeser E and Vigdor J (2008) When are ghettos bad? Journal of Urban Economics 63(3), 759-774.

Dahlberg M, Edmark K and Berg H (2017) Revisiting the relationship between ethnic diversity and preferences for redistribution. Scandinavian Journal of Economics 119(2), 288-294.

Dancygier R (2017) Dilemmas of Inclusion: Muslims in European Politics. Princeton, NJ: Princeton University. 
Dancygier R et al. (2015) Why are immigrants underrepresented in politics? American Political Science Review 109(4), 703-724.

de Rooij E (2012) Patterns of immigrant political participation. European Sociological Review 28(4), 455-481.

Edin PA, Fredriksson P and Åslund O (2003) Ethnic enclaves and the economic success of immigrants. Quarterly Journal of Economics 118(1), 329-357.

Fieldhouse E and Cutts D (2008a) Mobilisation or marginalisation? Political Studies 56(2), 333-354.

Fieldhouse E and Cutts D (2008b) Diversity, density and turnout. Political Geography 27(5), 530-548.

Grönqvist H, Johansson P and Niknami S (2012) Income inequality and health. Journal of Health Economics 31(4), 617-629.

Imai K et al. (2011) Unpacking the black box of causality. American Political Science Review 105(4), 765-789.

Laurence J and Heath A (2008) Predictors of Community Cohesion. London: Survey Department for Communities and Local Government.

Leighley J (2001) Strength in Numbers? Princeton, NJ: Princeton University Press.

Lindgren, KO, Nicholson MD, Oskarsson S (2020) "Replication Data for "Immigrant Representation and Local Ethnic Concentration: Evidence from a Swedish Refugee Placement Program””, https://doi.org/10.7910/DVN/DDVYJI, Harvard Dataverse, V1

Lipset S et al. (1954) The psychology of voting. In Lindzey G (ed.), Handbook of Social Psychology. Reading, MA: Addison-Wesley, pp. 1124-1175.

Lundh, C, and Ohlsson, R (1999) Från arbetskraftsimport till flyktinginvandring [From Labor Immigration to Refugee Immigration]. Stockholm: SNS Förlag.

Mansbridge J (1999) Should blacks represent blacks and women represent women? Journal of Politics 61(3), 628-657.

Marbach M and Hangartner D (2019) Profiling compliers and non-compliers for instrumental variable analysis. unpublished manuscript. Available from https://dx.doi.org/10.2139/ssrn.3380247.

Martén L, Hainmueller J and Hangartner D (2019) Ethnic networks can foster the economic integration of refugees. Proceedings of the National Academy of Sciences 116(33), 16280-16285.

Maxwell R (2012) Ethnic Minority Migrants in Britain and France: Integration Trade-Offs. New York: Cambridge University Press.

Maxwell R (2013) The integration trade-offs of political representation. European Political Science 12(4), 467-478.

Nekby L and Pettersson-Lidbom P (2017) Revisiting the relationship between ethnic diversity and preferences for redistribution. Scandinavian Journal of Economics 119(2), 268-287.

Nilsson $\AA$ (2004) Efterkrigstidens invandring och utvandring [Immigration and Emigration in the Post-War Period]. Stockholm: Statistics Sweden.

Norris P and Lovenduski J (1995) Political Recruitment: Gender, Race and Class in the British Parliament. Cambridge: Cambridge University Press.

Piil-Damm A (2009) Ethnic enclaves and immigrant labor market outcomes. Journal of Labor Economics 27(2), 281-314.

Piore M (1979) Birds of Passage: Migrant Labor and Industrial Societies. Cambridge: Cambridge University Press.

Portes A and Mozo R (1985) The political adaptation process of Cubans and other ethnic minorities in the United States. International Migration Review 19(1), 35-63.

Strömblad P and Myrberg G (2013) Urban inequality and political recruitment. Urban Studies 50(5), 1049-1065.

Verba S and Nie N (1972) Participation in America. New York: Harper and Row.

Vervoort M (2012) Ethnic concentration in the neighbourhood and ethnic minorities' social integration: weak and strong social ties examined. Urban Studies 49(4), 897-915.

Wass $\mathbf{H}$ et al. (2015) Engaging immigrants? Examining the correlates of electoral participation among voters with migration backgrounds. Journal of Elections, Public Opinion and Parties 25(4), 407-424.

Wenström A (2013) Personal interview, 8 August.

Wilson K and Portes A (1980) Immigrant enclaves. American Journal of Sociology 86(2), 295-319.

Cite this article: Lindgren K-O, Nicholson MD, Oskarsson S (2022). Immigrant Political Representation and Local Ethnic Concentration: Evidence from a Swedish Refugee Placement Program. British Journal of Political Science 52, 997-1012. https://doi.org/10.1017/S0007123420000824 